\title{
PERFECIT Y DENEGACIÓN FINAL DEL CONTRATO HISTORIOGRÁFICO EN EL FRAY GERUNDIO DE CAMPAZAS
}

\author{
Jorge Chen Sham
}

\begin{abstract}
The analysis of every liminar space must also incluide the last phrase of a text. To this effect I propose a new methodological tool for a better understanding of the communicative situation of every text. In the case of Fray Gerundio de Campazas, the perfecit destroys the historiographic contract proposed in the author's prologue and forces the text into a hermenuetic drift that has greater significance for the satirical scope requiered to neutralise the ideological stance.
\end{abstract}

En un afán por completar o complementar la teoría del incipit, postulamos una teoría del perfecit que tendría su radio de acción en la última frase del texto, pues entre la última frase y el mundo se toma también una decisión, se arriesga un sentido que captura todo relato. Así, el término perfecit surgió de la necesidad de presentar una herramienta metodológica, capaz de abordar y enfrentar el cierre de todo relatol, sobre todo en lo que se refiere a la estrategia retórica (contrato de lectura), en la medida en que se inserta dentro de una estrategia comunicativa que se encuentra formulada como espacio liminar del texto (Chen 1987:50) y se construye a partir de su correlato, incipere ("empezar, comenzar, emprender una acción") en la misma persona y el mismo tiempo verbal, de perficere ("llevar a término una acción, terminar, hacer perfectamente").

Tal precisión metodológica obedece al carácter estratégico que ofrece cualquier cierre para la interpretación del texto, como lo es en el caso de la Historia del famoso predicador fray Gerundio de Campazas (Madrid: 1758, I tomo; Madrid: 1770, II tomo)2 ; veamos, pues, su final:

Pero, recobrados los espíritus y dándome una palmadita en la frente, me acordé que todo esto ya lo había dicho yo en mi prólogo, protestando que yo era el padre, la madre, el hacedor y el criador de fray Gerundio; conque, lector mío, vamos a otra cosa; y cátate el cuento acabado (Isla 1964: 270) ${ }^{3}$

A primera vista se trata de una reivindicación autorial del narrador, quien deja patente su paternidad; pero para hacerlo, declara abiertamente el carácter ficcional del texto ("el cuento acabado") remitiendo al paratexto, lo cual provoca la ruptura del contrato historiográfico, propuesto con el sintagma genérico "puntual y verídica historia". 
Para comprender esta ruptura final, ficción vs. historia, hay que retomar el último capítulo (Libro VI, Cap. 4) en donde el narrador autorial irrumpe asegurando un comentario sobre el acto de narración. En efecto, este capítulo constituye una perfecta intromisión de la voz narrativa, que habla de las funciones propias a su papel, controlar la información y atestar la verdad sin que sea posible detener tal deriva comunicativa, pues el texto, como lo ha demostrado Jurado, incorpora fragmentos de piezas oratorias de importantes y contemporáneos predicadores religiosos (1989: 102) para censurarlos y criticarlos. De esta forma se comprende la ira y la rápida delación al Tribunal de Inquisición y el componente satírico puesto tan visiblemente. Por esta razón, no podemos detenernos únicamente en la frase final, pues ella forma parte de una estrategia hermenéutica que conduce a evaluar (o a revaluar) el contrato de lectura implícitamente pactado entre el narrador, que se califica a sí mismo como autor, y el narratario. Agreguemos, además, que es la fidelidad a este contrato historiográfico la causa de su propio cuestionamiento.

Dada la importancia que adquieren las fuentes en una obra historica, el narrador se siente obligado a informar sobre el origen de los palimpsestos que han servido para escribir la obra de fray Gerundio, un viajero, excelente en lenguas orientales, los trajo de Egipto; pero, lamentablemente muere y los documentos se esparcen por toda España, aunque gran parte de ellos permanecieron en el archivo de Cotanes, al cual tuvo acceso gracias a sus investigaciones rigurosas. En este momento, se da cuenta de que los documentos están escritos en lenguas orientales, de las cuales no tiene conocimiento. Pretende dejar inconcluso su trabajo, pero fortuitamente aparece un co-epíscopo armenio que recorre la corte española en procura de limosnas y al cual hospeda el narrador por largo tiempo; en retribución a su anfitrión, este co-epíscopo traduce los documentos en un tiempo récord de un mes.

A partir de esta traducción numerada y autentificada folio tras folio con la firma y el sello del co-epíscopo (autenticidad y legalidad de la traducción), el narrador se designa como el productor de la vida y hechos de Gerundio. Confiesa que ha ordenado cronológicamente el relato y confrontado, en algunos casos, las distintas versiones; todo esto en un tiempo sumamente largo, dos años, ya que considera que la empresa ha demandado mucho sacrificio y duro trabajo, al cabo de los cuales logra componer las dos primeras partes de la historia. La llegada de un profesor de la Universidad de Oxford, especialista en lenguas orientales, que pide la hospitalidad del narrador, interrumpe su trabajo y el comienzo de la tercera parte, lo que le permite verificar la validez y la coherencia de su relato, pues conociendo la erudición del profesor, le solicita que confronte su historia con los documentos de fuente. El profesor lo hace en seis días y emite un juicio desfavorable que apunta hacia la factura del texto, es decir, hacia el contrato genérico; anuncia que, en realidad, la obra que ha escrito es una pura ficción:

(...) porque creyendo vuestra merced que ha trabajado una obra exacta, verdadera, puntual y fiel, -cualidades que, cuanto es de su parte de vuestra merced, verdaderamente la asisten-, ha gastado el calor intelectual en disponer la relación más falsa, más embustera, más fingida y más infiel que podía caber en la humana fantasía. Si, como vuestra merced la llama historia, la llamara novela , en mi dictamen no se había escrito cosa mejor, ni de más gracia, ni de mayor utilidad (...) Nada tiene de historia, porque toda ella es una pura ficción. (Isla 1964:259-260) 
La opinión del profesor es categórica: opone historia vs. novela, relacionando este último término a ficción. Esta dicotomía es sumamente fuerte durante el siglo XVIII español, en donde novela era sinónimo de mentiras en su acepción más corriente, pues recordemos que novela entraba en correlación con fábula y ficción, de ahí su valor peyorativo, como lo recuerda Lázaro Almanza (1981:198-199), o como historias de aventuras que atentan contra la moral y la religión, en su acepción especializada; agrega al respecto Iris Zavala: "La intransigencia inquisitorial es poco propicia a la creación, pero lo que distingue al calificador del siglo XVIII es que se preocupa más por la literatura de ficción que sus antecesores. Toma conciencia de que a través de la fantasía y la fábula se podía convencer y subvertir a los indoctos (...)" (1983:515). Mientras que historia es considerado el género noble y grave, por medio del cual las enseñanzas tienen un mejor cauce.

El profesor orientalista pone, si observamos con precisión, el estatuto de la obra en entredicho; de ninguna manera se trata de un cuestionamiento del narrador, puesto que él ha seguido, de buena fe, la traducción del co-epíscopo. El cuestionamiento no es sólo de su trabajo (lo que dicen los documentos a propósito de fray Gerundio), sino también de su competencia y autoridad: "Todas estas son fuertes señales de que el supuesto co-epíscopo debía ser un picarón, un tunatón, un vagamundo de los que (...) con sus hipócritas artificios engañan tal vez a personajes que tenían motivo para no dejarse sorprender con tanta facilidad" (Isla 1964: 261). Es así como el narrador ha sido víctima de un burlador que ha abusado de criterios de autentificación para hacer pasar las mentiras por verdades: certificar la traducción, utilizar su sello episcopal y su firma. Sin embargo hay algo peor a sus ojos, el falso traductor (como falso cronicón) no ha respetado los documentos introduciendo sus propias observaciones e ideas, de manera que ha falseado y desvirtuado los documentos y la posible credibilidad. En efecto, el profesor duda de la precisión documental del co-epíscopo, porque los pormenores de la vida de fray Gerundio, que él introduce, son de su invención, aún si los documentos describen, en algunos pasajes, el retrato de un predicador:

No hay ni el más mínimo rasgo de eso en todo lo que he registrado, porque al predicador de que se trata no se le señala estado ni profesión. Por eso, todo cuanto se dice de su vocación, noviciado, estudios, empleos, etcétera, se lo regaló de su bella gracia el ilustrísimo señor Isaac Ibrahim Abusemblat, co-epíscopo del Gran Cairo (Isla 1964: 263).

Por lo tanto, eleva su voz contra la inadecuación de la traducción de los palimpsestos: "no se encuentran en los documentos originales" (Isla 1964: 263) "o todo esto fue de su invención, y nada de esos papeles" ( Isla 1964: 265).

Esta interpretación final, que clausura el texto y que es proporcionada por un personaje de la diégesis, pues este profesor se presenta como un lector privilegiado del texto, único lector interno en la medida en que se hace partícipe al narrador de sus observaciones sobre el origen apócrifo de ciertos pasajes, la autenticidad de unos, el rechazo de otros; sobre problemas de verosimilitud o sobre el acierto en la descripción de retratos y acciones. Destruye el pacto historiográfico sobre el cual el narrador-autor construye su obra; los documentos no han sido fielmente traducidos. Como tal este contrato historiográfico se establece en dos niveles: 
a. contrato entre el traductor y el narrador, b. contrato entre el narrador y el narratario.

El primer contrato se apoya sobre la garantía ofrecida por el co-epíscopo armenio, quien autentificaba, con sello y firma, la traducción fidedigna de los documentos. Según la palabra del profesor orientalista, ésta es una sarta de mentiras de un pseudo-traductor. En cambio el segundo contrato hubiera quedado indemne, pues el narrador salva toda su responsabilidad, al imputar el acto de timo y falsificación únicamente al co-epíscopo armenio; pero están las palabras finales del texto para suscitar un desenlace inesperado que revuelve aún más las cosas. El perfecit del texto destruye el segundo contrato, haciendo que la desconfianza se apodere también del narratario. De esta manera, la adhesión del narrador a la autoridad del profesor en lenguas orientales, así como la remisión al prólogo en morrión ponen en entredicho su palabra y el grado de fiabilidad que pueda otorgársele de ahora en adelante ("me acordé que todo esto ya lo había dicho yo en mi prólogo").

¿Por qué propone un contrato historiográfico, cuando ya había declarado su paternidad, es decir, el estatuto ficcional de la obra? ${ }^{4}$. El narrador ha fingido desconocer el carácter ficcional de su obra, cuando en realidad ya lo sabía. La aparición milagrosa del profesor que desautoriza la traducción del armenio le permite confesar que todo era de su conocimiento: es un engaño, y él, un mentiroso, porque prometió desde el comienzo del relato, la autenticidad de la información. Y todo se hace en provecho de la instancia paratextual, pues remite al lector a las explicaciones del prólogo, en la medida en que el paratexto asume la interpretación del texto.

Este proceso de negación hermenéutica con el cual logra finalizar la obra conlleva el germen de su propia destrucción. Descubrimos una aporía surgida de la contigüidad de dos contratos y de dos verdades; y esta contigüidad, producida por el hecho de que el narrador convoca en el perfecit ambos contratos, activa un espacio de ambigüedad en la conjunción de dos aserciones, lo verdadero y lo falso: el perfecit afirma que el cotexto ${ }^{5}$, en donde se programa el contrato historiográfico, es falso, confirmando (o reafirmando) que lo verdadero es el paratexto, focalizado por el prólogo con morrión ; recordemos, con Alain Berrendonner, que el verbo confirmar tiene como presupuesto la aserción "ya se te ha dicho que..." (1981: 49), con lo cual el contrato establece su circularidad.

Para comprender el funcionamiento de esta doble aserción, hay que reconstituir la cadena de relevos pragmáticos que invierten el estatuto de texto en el nivel de la situación comunicativa; el texto requiere de personajes que acrediten y garanticen la escritura 6 , es decir, requiere de un cuerpo de autoridades que, por su testimonio y palabra, justifiquen el texto literario, actuando como un proceso de validación: a) el viajero que trae los documentos; b) el coepíscopo armenio que los traduce; c) el narrador-historiador que, siguiendo la traducción, realiza su obra y d) el profesor que confronta los documentos, la traducción y la obra. El es el único que ha leído las tres etapas de la escritura; el narrador solo conoce dos ( documentos y traducción).

Tal y como ellos lo confirman, la escritura del Fray Gerundio pasa por tres etapas: documentos $\longrightarrow$ traducción $\longrightarrow$ historia. El punto de conflicto es encarnado por la traducción, mediación obligatoria entre la materia prima y el producto; lo que implica que consideremos al traductor como una mediación. Este traductor compromete su palabra y certifica que su traducción 
es fiel a los documentos, comprometiendo a su turno al narrador, a través de su buena fe, que compromete también la suya ante el narratario. Los unos se hacen fiadores de los otros. Esta situación primera se cuestiona con la intervención del profesor, quien advierte de la falsa traducción, comprometiendo también su palabra. De esta manera, la ruptura del contrato historiográfico pasa por la aceptación o no aceptación de la palabra de una de las autoridades: el profesor o el co-epíscopo. El narrador toma posición en favor de las pruebas aportadas por el profesor; es normal, ya que no conoce lo que dicen los documentos. Aquel concluye que el armenio lo ha engañado y que la historia de la vida de Gerundio es ficción.

Pero afirma en seguida que ya sabía del carácter ficticio de su obra. Esta afirmación cuestiona, una vez más, la situación comunicativa: si el armenio es un farsante, de igual manera el traductor lo es también; no solamente ha engañado al narratario sino que le ha mentido. Sin embargo, el hecho de fingir se encuentra tanto en el contrato roto como en el gesto de neutralizarlo, de modo que toda palabra imputada, aún si conlleva la intención de decir la verdad, es arrastrada por el acto primero de mentira. Así, con el perfecit, la cadena de autoridades se derrumba, produciendo un espacio de ambigüedad en donde la intencionalidad del narrador (hacer valer la autoridad del prólogo) se vuelve contra él. En este contexto de desconfianza y engaño, el acercamiento de ambos contratos, un contrato paratextual (ficcional) y un contrato cotextual (historiográfico), únicamente provoca su propia pérdida, su cuestionamiento. Esto produce el mismo efecto que si el historiador introdujera, en sus obras, mentiras o hechos no comprobados, como lo recuerda Jacinto Segura en su manual para historiadores: "La realidad de los sucessos haze impressión en el ánimo de los Lectores. Las noticias falsas quitan el crédito a la Historia, y de ella ni las verdades se creen “(1736: 13).

Si la inclusión de mentiras pone en duda la credibilidad y autenticidad de un contrato historiográfico, lo mismo vale para el Fray Gerundio en donde quién puede asegurar que si el narrador mintió una vez, siga mintiendo, y en donde tampoco se puede asegurar que se trate, al fin y al cabo, de un contrato ficcional. Por la fuerza ilocutiva del acto de mentir, toda palabra es de ahora en adelante ni verdad ni mentira, ni ficción ni historia.

Ahora bien, desde el punto de vista de los implícitos habrá que interrogar la negatividad derivada de la aserción falso-verdadero. Este procedimiento, que destruye el contrato historiográfico y pone en duda el ficcional, puede ser interpretado en términos de una técnica retórica, llamada denegación por Francesco Orlando. Esta concierne particularmente a los textos literarios en que el narrador, que asume el papel de actor o personaje, se pronuncia contra, refuta, condena, critica, alaba, favorece, etc; instituciones, costumbres, personajes, teorías, libros. Para Orlando, la denegación busca, ante todo, la formación de un compromiso mediante una serie de transformaciones negativas que se orientan a suspender toda responsabilidad:

(...) en gran número de textos el gesto de precaución que puede escamotear la crítica misma, así como el sujeto y su objeto, permanece sin llegar a la formulación literaria y únicamente se orienta a engañar un censor, a evitar un peligro (...) Tan pronto como el gesto de precaución se hace ficticio (...) tan pronto como la situación de extrañedad se traduce en ficción -pudiendo ser aplicado al escamoteo del verbo criticar-, nuestro sistema de denegaciones está en marcha (1980: 85, traducción nuestra) 
Y en efecto, la interpretación final del texto cumple las tres condiciones que Orlando atribuye a esta técnica:

a) El gesto de precaución es ficticio, desde el momento en que el narrador confirma su mentira y remite al lector hacia el paratexto, en donde declara el estatuto ficcional de su obra.

b) La extrañedad para lograr el distanciamiento adecuado. En primer lugar están los documentos, escritos en lenguas orientales de las cuales el narrador no tiene ni el mínimo conocimiento y que, supuestamente, traduce el co-epíscopo armenio. A esta situación inicial, se agrega otra que destruye la primera; aparece un profesor especialista en lenguas orientales, quien afirma la no adecuación de la traducción a los documentos. Toda la responsabilidad sobre el estatuto del texto recae en extranjeros, cuyo testimonio sirve de garantŕa a su actuación, de modo que el narrador se sustrae a su propia responsabilidad.

c) El escamoteo de toda responsabilidad y de toda crítica, en la medida en que el sistema de implicaciones de extrañedad ofrece la posibilidad de suspender toda responsabilidad ante la palabra dada: el narrador escamotea el acto de criticar, programado por el contrato paratextual bajo el protocolo de sátira de los malos predicadores barrocos. No se le puede censurar por una sátira que denigra a los predicadores religiosos, pues lo que ha escrito se basó en una traducción supuesta de documentos, como tampoco se le puede censurar porque lo que ha escrito él es ficción. Recordemos que la noción de sátira presupone, gracias a su restricción didáctico-utilitaria, un criterio de sinceridad y autenticidad para la censura o la crítica; dicho de otro modo, el concepto de sátira presupone una relación referencial entre lo que se critica y el texto que critica, pues "La ficción satírica presenta la enunciación del discurso como respuesta a una situación histórica real" (Schwartz 1985: 215). Por eso, cuando el narrador dice que el texto es ficción, desmiente el carácter satírico del texto, desmiente el carácter referencial de lo que escribe.

Por lo tanto, es el perfecit del Fray Gerundio de Campazas el que posibilita la puesta en marcha de la denegación, produciéndose una serie de implicaciones pragmáticas. Si en los textos denotativos se puede declarar YO CRITICO X, en un texto literario tal enunciado se transforma en un YO CRITICO UN OTRO X, con las siguientes implicaciones:

1. No soy yo quien / critica / $\mathrm{x}$

2. Yo/no critico/ $\mathrm{x}$

3. Yo / critico / no ese $\mathrm{x}$

El enunciado 1 deja fuera de todo cuestionamiento la responsabilidad del sujeto; el enunciado 2 escamotea la acción de criticar y el enunciado 3 escamotea la identidad del objeto. Pero resultan aún más interesantes las consecuencias de estas implicaciones:

1. Es otro quien critica $x$.

2. Es otra cosa lo que yo hago.

3. Es otra cosa lo que yo critico. 
He aquí puestos al descubierto los mecanismos de denegación de nuestro texto en estudio: cuando se le dice a alguien que él critica $\mathrm{x}$, podrá responder negativa o afirmativamente; por supuesto, es la negación la que nos interesa. Si lo niega, es porque, en realidad, no lo ha hecho o porque prefiere sustraerse a tal afirmación, ya que ha hecho, en efecto, una crítica. De manera que se quiere ocultar a todo precio la responsabilidad; sin embargo, su resultado es inverso desde el momento en que se convoca el prólogo con morrión, lugar en donde se habla abiertamente de sátira.

Si la interpretación final se dirigía, tal vez conscientemente, a rebasar las posibles medidas de censura, y prohibición del texto o las posibles críticas del autor material en tanto que lo descompromete y lo deja fuera de todo cuestionamiento, ella fracasa y deja emerger el miedo y la amenaza que obsesionan al texto. Si se insiste en negar algo, es porque se tiene miedo a las consecuencias de la afirmación; prueba de ello es la famosa polémica que desata el Fray Gerundio y que culmina con la censura inquisitorial, sus consecuencias pragmáticas en los lectores contemporáneos a la puesta en circulación del texto las analizo en mi artículo "Recepción literaria y contrato satírico" (Chen 1992: 125-141). Así, la denegación hace surgir aquello que el texto, a través de la instancia narrativa de la cual el narrador es una realización, reprime y no puede decir abiertamente, precisamente porque teme represalias en su contra.

\section{Notas}

1. El término perfecit surgió de la necesidad de presentar una herramienta metodológica, capaz de abordar y enfrentar el cierre de todo relato, sobre todo en lo que se refiere a la estrategia retórica (contrato de lectura). La estudiante Merceditas Solís desarrollaba, en su momento, su tesis de licenciatura alrededor de este concepto en "Una teoría del perfecit para Cien años de soledad"; a ella agradezco su diálogo fructífero y la
acuñación del término.

2. Siguiendo las observaciones de Julio Jurado sobre las ediciones furtivas del texto, me parece que la primera edición completa del tomo segundo es la que aparece en la fecha de 1770 . Hemos de recordar que, sobre el texto, pesaba una prohibición inquisitorial que obligó a imprimirlo furtivamente, lo cual hace difícil cualquier intento de establecer la edición príncipe. Cfr. de Jurado (1982 y 1983).

3. Utilizamos la edición de Russell Sebold en la colección Clásicos Castellanos, Madrid, Espasa-Calpe, 1960 1964 , la mejor y más completa edición hasta el momento.

4. Recordemos que el prólogo con morrión se inicia con una declaración de autenticidad de la obra.

5. El término cotexto surge de la necesidad de incluir las instancias paratextuales, sacándolas de una cierta marginalidad, dentro de la dinámica comunicativa de todo texto literario, el cual tendría dos espacios bien delimitados: un paratexto (aquellos segmentos que encuadran o acompañan un texto) y un cotexto (el texto
propiamente dicho).

6. Se trata de una delegación de la autoridad, en el sentido de que se recurre a los personajes con el fin de que sean ellos los que tomen a su cargo, ya sea el comentario del texto, ya sea la justificación misma de la es-
critura, Cfr. Dallënbach 1977 .

\section{Bibliografia}

Almanza, Lázaro. 1981. "Notas sobre la voz novela en Feijoo y en la literatura de su época". II Simposio sobre el Padre Feijoo y su siglo, 197-203. Oviedo: Centro de Estudios del s. XVIII. 
Berrendoner, Alain. 1981. Eléments de pragmatique linguistique. París: Editions de Minuit.

Chen Sham, Jorge. 1987. "El libro de la patria: el espacio liminar del texto y la lectura de la apertura". Káñina. 11 (1) 40-57.

1992. "Recepción literaria y contrato satírico: un acercamiento a la polémica desatada por el Fray Gerundio de Campazas". Káñina. 16 (1) 125-141.

Dallënbach, Lucien. 1977. Le récit spéculaire: essai sur la mise en abyme. París: Editions du Seuil.

Isla, José Francisco de. 1964. Historia del famoso predicador fray Gerundio de Campazas. Madrid: Editorial Espasa-Calpe, Tomo IV.

Jurado, Julio. 1982. "Ediciones 1758 del Fray Gerundio de Campazas”. Thesavrvs. 37 (3): 544 -580. 1985. "Ediciones tempranas del Fray Gerundio de Campazas". Bulletin Hispanique. 87 (1-2): 137-165.

1989." El Fray Gerundio y la oratoria sagrada barroca". Edad de Oro . 8: 97-105.

Orlando, Francesco. 1981. "Rhétorique des Lumiéres et dénégation freudienne". Poétique. 41:78-89.

Schwartz Lerner, Lía. 1985. "En torno a la enunciación en la sátira: los casos de El Crotalón y los Sueños de Quevedo". Lexis. 9 (2): 209-227.

Segura, Hyacinthus. 1736. Norte crítico con las reglas más ciertas para la discreción en la Historia, y un tratado preliminar para la instrucción de históricos principiantes. Valencia: Antonio Balle. Tomo I.

Zavala, Iris. 1983. "Inquisición, erotismo, pornografía y normas literarias en el siglo XVIII". Anales de Literatura Española. 2: 509-29. 